\title{
Fatty acid profiles, meat quality, and sensory attributes of organic versus conventional dairy beef steers
}

\author{
E. A. Bjorklund, B. J. Heins, ${ }^{1}$ A. DiCostanzo, and H. Chester-Jones \\ Department of Animal Science, University of Minnesota, St. Paul 55108
}

\begin{abstract}
Meat from Holstein and crossbred organic and conventional dairy steers were evaluated and compared for fatty acid profiles, meat quality, sensory attributes, and consumer acceptance. Bull calves $(\mathrm{n}=49)$ were randomly assigned to 1 of 3 replicated groups: conventional (CONV), organic (ORG, pasture + concentrate), or grass-fed organic (GRS) and were born at the University of Minnesota West Central Research and Outreach Center (Morris, MN) between March and May 2011. The CONV steers $(\mathrm{n}=16)$ were fed a diet that contained $80 \%$ concentrate and $20 \%$ forage, and ORG steers $(\mathrm{n}=16)$ were fed a diet of organic corn, organic corn silage, and organic protein supplement. Furthermore, ORG steers consumed at least 30\% of diet dry matter of high-quality organic pasture during the grazing season. The GRS steers $(\mathrm{n}=17)$ consumed $100 \%$ forage from pasture during the grazing season and high-quality hay or hay silage during the nongrazing season. The ORG steers had fat that was greater in oleic acid (C18:1) than the GRS and CONV steers (47.1, 36.1, and $39.9 \%$, respectively). The GRS steers $(21.9 \%)$ were lower for monounsaturated fat than the ORG (42.1\%) and CONV (40.4\%) steers. Furthermore, the GRS steers tended to have greater n-3 fat and had lower n- 6 fat than the ORG and CONV steers. Consequently, the GRS (1.4\%) steers had a lower n-6-to-n-3 fat ratio than the ORG (12.9\%) and CONV (10.0\%) steers. The GRS $(2.6 \mathrm{~kg})$ steers had steaks that were not different for Warner-Bratzler shear force than ORG $(2.3 \mathrm{~kg})$ steaks; however, the GRS steaks tended to have greater shear force than the CONV $(2.0 \mathrm{~kg})$ steaks. The 3 steer group had steaks that were not different for color brightness $\left(\mathrm{L}^{*} ; 0=\right.$ black and $100=$ white) and yellowness/blueness $\left(b^{*}\right.$; positive values $=$ yellow and negative values $=$ blue) values; however, the GRS (10.5) steaks had lower redness/greenness (a*; positive values $=$ red and negative values $=$ green) values than CONV (14.5) steaks. For sensory attributes (0- to
\end{abstract}

Received May 1, 2013.

Accepted December 3, 2013.

${ }^{1}$ Corresponding author: hein0106@umn.edu 120-point scale), no differences were observed for ORG (71.3) and CONV (69.2) steers for overall consumer liking of the beef; however, the GRS (56.3) steers had the lowest overall liking among beef consumers. The ORG (73.3) steers had greater flavor liking than the GRS (56.8) and CONV (69.2) steers. Conversely, the GRS (6.3) steers had the highest scores for off-flavor (0to 20-point scale) compared with the ORG (3.9) and CONV (4.1) steers. The results of the current study suggest that a potential market may exist for organic grass-fed dairy steers in the United States, but quality and consistency of the beef needs to be improved.

Key words: organic, dairy steer, grass-fed, n-3 fatty acid

\section{INTRODUCTION}

The organic beef industry is in the early stages of development in the United States; however, markets for organic meat have expanded rapidly over the past decade as consumers consider potential human health and environmental benefits (Dimitri and Oberholtzer, 2009). As consumers are demanding natural, local, organic, and grass-fed animal products, an opportunity exists for organic dairy producers to capitalize on the growing organic beef industry (Gillespie and Nehring, 2013).

The USDA National Organic Program (NOP) standards became effective in 2002 and address production, processing and labeling, certification, recordkeeping, and inputs allowed in organic farming and processing (USDA-NOP, 2012). Pasture and land for production of organic crops must not have had any prohibited substances, such as synthetic fertilizers or pesticides, applied to it $3 \mathrm{yr}$ before the first use of the crop for organic purposes (USDA-NOP, 2012). All certified organic livestock must be fed organic feed from certified organic land, and all cattle over 6 mo of age are required to receive at least $30 \%$ of their DMI from pasture for at least $120 \mathrm{~d}$ during the grazing season each year.

Growth hormones and antibiotics are not allowed to be provided to livestock in organic production systems. However, it is forbidden to withhold medical treatment from a sick animal to keep its organic status (USDA- 
NOP, 2012). If beef is to be labeled and sold as organic, it must be harvested at a plant that is certified organic and federally or state inspected.

Most beef consumers in the United States prefer the taste of conventional grain-fed beef, and the United States cattle industry most commonly finishes animals on a corn-based ration (Daley et al., 2010). Conversely, in the European Union, beef consumers assert that meat from livestock managed under less intensive production systems has superior taste than meat from intensive production systems (Priolo et al., 2001). Currently, several consumers are evaluating their food-purchasing decisions and are considering pasture-fed beef as an alternative (Steinberg et al., 2009).

Saturated fat, trans fat, and cholesterol have become major health concerns for consumers (Daley et al., 2010). Conjugated linoleic acids are a group of FA that possess human health benefits (Razminowicz et al., 2006), and conjugated linoleic acids and n-3 FA are greater in cattle fed high-forage and pasture diets compared with cattle fed high-grain rations (Poulson et al., 2004; Daley et al., 2010). However, for consumer sensory evaluation, Steinberg et al. (2009) reported that United States beef consumers preferred grain-fed beef compared with grass-fed beef for flavor, juiciness, and tenderness.

Organic dairy bull calves may represent a potential resource for pasture-raised beef in the United States as an alternative to conventional feedlot-raised beef. The hypothesis of the current study was that meat from conventional dairy steers would have greater meat quality and greater consumer acceptance than meat from organic dairy steers; however, the meat from organic dairy steers would have greater levels of beneficial FA than meat from conventional dairy steers. Therefore, the objectives of this study were to compare conventional (CONV), organic (ORG), and organic grass-fed (GRS) dairy steers for FA profiles, Warner-Bratzler shear force (WBSF), objective color scores, and consumer acceptability. A companion paper (Bjorklund et al., 2014) reported results from the same steers for growth performance, carcass characteristics, and profitability.

\section{MATERIALS AND METHODS}

The study was conducted at the University of Minnesota West Central Research and Outreach Center (WCROC; Morris) and all animal care and management was approved by the University of Minnesota Institutional Animal Care and Use Committee recommendations (Animal Subjects Code no. 1104B98412). The University of Minnesota WCROC organic dairy has been certified organic since June 2010. A detailed description of the study and management of the organic dairy beef steers compared with conventional dairy beef steers is in Bjorklund et al. (2014).

Dairy bull calves $(\mathrm{n}=49)$ were born at the University of Minnesota WCROC between March and May 2011. Breed groups of calves were Holsteins (HO; n $=9)$ selected for high production; Holsteins $(\mathrm{n}=11)$ maintained at 1964 breed average level; crossbreds (n $=19$ ) including combinations of HO, Montbéliarde, and Swedish Red; and crossbreds $(\mathrm{n}=10)$ including combinations of HO, Jersey, Swedish Red (HI), and Normande (LO). Calves were assigned to 1 of 3 replicated groups (2 pens per group) at birth: $\mathbf{C O N V}(\mathrm{n}=$ $16)$, ORG $(\mathrm{n}=16)$, or GRS $(\mathrm{n}=17)$.

During the preweaning phase, all calves were fed $1.5 \%$ of birth weight of $13 \%$ TS organic unpasteurized whole milk once daily and weaned when the youngest calf in the group reached $90 \mathrm{~d}$ of age and consumption of starter averaged $0.91 \mathrm{~kg}$ starter/calf per day. The CONV calves were fed a conventional calf starter and ORG steers were fed an organic calf starter from $3 \mathrm{~d}$ of age. However, GRS steers were not provided calf starter, but were fed free-choice organic grass hay from $3 \mathrm{~d}$ of age. Postweaning, the CONV steers were moved to a cross-ventilated feedlot barn at the WCROC with $2.79 \mathrm{~m}^{2} /$ head of space and fed a diet of $67 \%$ concentrate and $33 \%$ roughage. Upon reaching a BW average of 204 $\mathrm{kg}$, CONV steers were fed a diet of $80 \%$ concentrate and $20 \%$ forage. The TMR consisted of corn silage, dried distillers grains with solubles, dry corn, grass hay, soybean meal, and minerals.

The ORG and GRS steers were moved to permanent organic cool-season pasture postweaning and rotated to a new paddock every $3 \mathrm{~d}$. For the ORG steers, at least $30 \%$ of DMI was from pasture during the grazing season. Furthermore, the ORG steers were supplemented with an organic TMR during the grazing and winter seasons containing organic corn, organic expelled soybean meal, organic corn silage, and organic-certified minerals. The GRS steers grazed pasture during the grazing season and were fed high-quality hay or hay silage during the nongrazing season, along with free-choice minerals during the grazing season.

\section{Strip Loin Collection}

Carcasses were selected randomly, within breed group, before carcass data collection and, subsequently, fabricated after chilling for $24 \mathrm{~h}$ according to North American Meat Processors guidelines (NAMP, 2002). One strip loin was removed from 8 carcasses from each treatment group, CONV (slaughter conducted on July 24, 2012), ORG (slaughter conducted on September 19, 2012), and GRS (slaughter conducted on November 13, 
2012). For the CONV and GRASS steers, 2 carcasses from each breed group were randomly selected for strip loin collection ( 8 in total), and 1 Holstein maintained at 1964 breed average level, $2 \mathrm{HO}, 3 \mathrm{HI}$, and 2 LO steers were randomly selected from the ORG steers for strip loin collection. Strip loins were identified using carcass identification tags during slaughter. Identified strip loins were followed through fabrication and vacuum packaged at a commercial abattoir [Tyson Fresh Meats Inc. (Dakota City, NE) for CONV steers, and Lorentz Meats (Cannon Falls, MN) for ORG and GRS steers]. The ORG and GRS steers were harvested at a different abattoir because Lorentz Meats was a National Organic Program-inspected facility, and Tyson Fresh Meats Inc. was not. The same research personnel collected all samples at both abattoirs. Meat samples from the CONV steers were in a freezer 2 mo longer than ORG steers and 4 mo longer than GRS steers until analyzed for WBSF and consumer sensory panel.

Strip loins were maintained at $2^{\circ} \mathrm{C}$ during transport to the University of Minnesota WCROC where they were unloaded and aged for $10 \mathrm{~d}$ postmortem at $2^{\circ} \mathrm{C}$ before further evaluation of meat quality and consumer acceptability. After aging, six 2.54-cm-thick, frozen steaks were cut from the cranial end of each strip loin. The most cranial steak of the 6 steaks cut from the frozen strip loin was used for WBSF analysis, 2 steaks were used for objective color score analysis, and the remaining 3 steaks were used for consumer panel sensory evaluation.

\section{FA Profiles}

Back fat samples (approximately $6.4 \times 0.5 \mathrm{~cm}$ ) were collected from 8 random carcasses from each treatment group $72 \mathrm{~h}$ postmortem at the commercial abattoir. The back fat samples were collected from the same carcasses that were used for strip loin collection. Samples were placed in air-tight plastic bags, transported on ice to the University of Minnesota WCROC, and frozen $\left(-20^{\circ} \mathrm{C}\right)$ until subsequent analysis. Eight frozen fat samples were chosen at random from each of the 3 treatment groups, were placed on ice packs in a polystyrene insulated container, and shipped to rtech Analytical Laboratories (Arden Hills, MN) for FA profile analysis.

Fatty acids from the 8 selected steers per group were determined according to the AOAC International method (AOAC International, 2002; method 996.06) by rtech Analytical Laboratories. Briefly, lipids were extracted from a 3-g sample, saponified, derivatized, and then run on a gas chromatograph to determine which FA were contained in the sample. Results were reported as a percentage of a specific FA in the total fat and the value of all FA added up to $100 \%$.

\section{Tenderness Determination and Objective Color Scores}

Tenderness was measured on a steak from each strip loin using the WBSF instrument (G-R Electric Manufacturing Co., Manhattan, KS). Steaks were removed from the freezer, thawed for $84 \mathrm{~h}$ at $4^{\circ} \mathrm{C}$, wrapped in aluminum foil, and then cooked in an electric oven to a final internal temperature of $71^{\circ} \mathrm{C}$. Internal temperature was monitored with a thermometer inserted into the geometric center of the steak. Each steak was cooled to room temperature and three $1.27-\mathrm{cm}$ cores were removed from each steak parallel to the muscle fiber orientation using a hand coring device. A single peak shear force measurement was obtained for each core.

The color of each steak was measured using a HunterLab MiniScan XE Plus spectrophotometer equipped with a 6-mm aperture (HunterLab Associates Inc., Reston, VA) to determine color coordinate values for brightness $\left(\mathbf{L}^{*} ; 0=\right.$ black and $100=$ white), redness/ greenness $\left(\mathbf{a}^{*}\right.$; positive values $=$ red and negative values = green), and yellowness/blueness ( $\mathbf{b}^{*}$; positive values $=$ yellow and negative values $=$ blue) following procedures of the Commission International de l'Eclairage (CIE, 1976). Readings for each of the $\mathrm{L}^{*}, \mathrm{a}^{*}$, and $\mathrm{b}^{*}$ values were taken at 3 spots on the surface of the steak exposed to the light; readings were averaged for each steak at the time of evaluation.

\section{Consumer Sensory Evaluation}

Procedures with human subjects for the consumer panel evaluation of sensory attributes were approved by the University of Minnesota Institutional Review Board. One hundred consumers were recruited by the University of Minnesota Food Science and Nutrition Sensory Center. Consumers were at least 18 yr old, had no food allergies, and had consumed cooked beef within the past month. All panelists were compensated $\$ 5$ for participating in the sensory panel. Steaks were thawed and cooked to an internal temperature of $71^{\circ} \mathrm{C}$ in the same manner as described for WBSF analysis. When steaks were removed from the oven, cubes of approximately $1 \times 1 \times 2.5 \mathrm{~cm}$ were placed in double boiler pots containing simmering water and the pots were replenished with cubes every $30 \mathrm{~min}$ to serve to the panelists for evaluation. Each panelist received 2 pieces of steak per sample in lidded $57-\mathrm{mL}$ plastic soufflé cups coded with random 3-digit numbers. To maintain sample serving temperature, cups were nested in insulated foam trays and kept warm with heated towels. The samples were served to panelists in 3 sets of 3 samples on 1 tray. The first set corresponded to replicate 1 , the second set corresponded to replicate 2 , and 
the third set corresponded to replicate 3 . The 3 samples within each set were balanced for order and carryover effects by personnel from the University of Minnesota Sensory Center using a Latin square design with SIMS Sensory Evaluation Testing Software (http://www. sims2000.com/).

Subjects were asked to taste 1 piece of the sample and rate it for overall liking, liking of flavor, liking of texture, and off-flavor. Samples were evaluated using a labeled affective magnitude scale. A mark was placed anywhere on the scale that appropriately described the panelist's liking of tenderness, flavor, texture, and overall liking $(0=$ greatest imaginable disliking and 120 $=$ greatest imaginable liking). Furthermore, panelists were then instructed to consume the second piece of meat and rate the intensity of toughness, intensity of juiciness, along with a rating for off-flavor $(0=$ none and $20=$ extremely tough, extremely juicy, and extremely intense, respectively). Panelists repeated all steps 2 additional times.

\section{Statistical Analysis}

For statistical analysis of FA profiles, WBSF, and objective color score, the independent variable was treatment group. All observations within pens were averaged for analysis. Additionally, for analysis of FA profiles, WBSF, and objective color scores, pen within group was included in the statistical model as a random effect, because pen was the experimental unit in the study. For consumer acceptability analysis, independent variables were fixed effects of treatment group, replicate, and the interaction of treatment group and replicate. Additionally, consumer subject and the interaction of consumer subject and treatment group were included as random effects in the model. For all measurements, PROC MIXED of SAS (SAS Institute, 2012) was used to obtain solutions and conduct the ANOVA. All treatment results are reported as least squares means, and significance was declared at $P<$ 0.05 . Additionally, a $\chi^{2}$ test (SAS Institute, 2012) was used to compare treatment groups for alternative measures of overall liking.

\section{RESULTS AND DISCUSSION}

\section{FA Analysis}

Least squares means and standard errors for FA for steer groups are in Table 1. The GRS, ORG, and CONV steers had the same values $(0.1 \%$ for each FA) for butyric (C4:0), caproic (C6:0), caprylic (C8:0), capric (C10:0), lauric (C12:0), tridecanoic (C13:0), my- ristelaidic (trans $\mathrm{C} 14: 1)$, pentadecenoic (C15:1), gamma linolenic (C18:3), arachidic (C20:0), eicosadienoic (C20:2), eicosatrienoic (C20:3), homogamma (C20:3), arachidonic (C20:4), eicosapentaenoic (C20:5), behenic (C22:0), docosanoic (C22:1), docosadienoic (C22:2), docosatrienoic (C22:3), docosatetraenoic (C22:4), docosapentaenoic (C22:5), docosahexaenoic (C22:6), tricosanoic (C23:0), lignoceric (C24:0), and nervonic $(\mathrm{C} 24: 1)$ acids and are not reported in Table 1.

Fat from GRS steers had greater $(P<0.05)$ means of palmitic (C16:0), stearic (C18:0), linoelaidic (C18:2T), linolenic (C18:3), and heneicosanoic (C21:0) acids than fat from ORG and CONV steers. Results are similar to those of Priolo et al. (2001), who found greater proportions of linolenic acid in grass-fed beef compared with conventional beef. Daley et al. (2010) reported that beef from grass-fed steers had greater amounts of stearic acid than grain-fed beef. Microorganisms in the rumen can differ based on feeding system and the organisms that are present when concentrates are a high percentage of the ration provide a reduced hydrogenation reaction compared with those present with a high grass-based diet (Priolo et al., 2001). The ORG steers had fat that was greater $(P<0.05)$ for oleic $(\mathrm{C} 18: 1)$ acids than fat from GRS and CONV steers, which is contrary to the findings of Daley et al. (2010), who reported greater levels of oleic acid in grain-fed beef than grass-fed beef. However, the ORG steers were fed a diet that consisted of $70 \%$ concentrates during the summer and $70 \%$ concentrate and $30 \%$ corn silage during the winter and, therefore, their corn-based diet likely contributed to the greater level of oleic acid in fat than that found in the GRS steers.

The fat from GRS steers had lower $(P<0.05)$ levels of monounsaturated fat $(21.9 \%)$ than the ORG $(42.1 \%)$ and CONV (40.4\%) steers. The 3 steer groups had fat that was not different for polyunsaturated fat. Furthermore, the GRS steers tended to have greater levels $(P$ $=0.08)$ of $\mathrm{n}-3$ fat $(0.50 \%)$ and lower levels $(P<0.05)$ of n-6 $(0.68 \%)$ fat than the ORG $(0.21$ and $2.1 \%$, respectively) and CONV (0.19 and 2.5\%, respectively) steers. Consequently, the n-6:n-3 ratio was lower $(P<0.05)$ for the GRS (1.4\%) steers compared with the ORG $(10.0 \%)$ and CONV (12.9\%) steers. The GRS steers tended to have lower levels $(P=0.08)$ of total triglycerides than CONV steers. The steer groups were not different for saturated fat and trans fat (unsaturated fat with trans-isomer FA). The results are similar to those of Razminowicz et al. (2006) and Cozzi et al. (2010), who reported that grass-fed beef had greater n-3 and lower n- 6 fat levels than conventional beef. In the current study, increased forage and grass intake may have increased the n-3 fat and decreased the n-6:n-3 ratio for 
Table 1. Least squares means and SE for FA for organically raised (pasture + concentrate and grass-fed) dairy steers compared with conventionally raised dairy steers

\begin{tabular}{|c|c|c|c|c|c|c|}
\hline FA & \multicolumn{6}{|c|}{ Dairy steers } \\
\hline \multicolumn{7}{|l|}{$\%$ weight of total fat } \\
\hline 14:0, myristic & $4.1^{\mathrm{a}}$ & 0.05 & $2.7^{\mathrm{b}}$ & 0.05 & $3.3^{\mathrm{c}}$ & 0.05 \\
\hline 14:1, myristoleic & $1.7^{\mathrm{a}}$ & 0.18 & $1.5^{\mathrm{a}}$ & 0.18 & $0.93^{\mathrm{b}}$ & 0.18 \\
\hline $16: 1$, palmitoleic & 6.1 & 0.71 & 6.2 & 0.71 & 4.9 & 0.71 \\
\hline trans $16: 1$, palmitelaidic & 0.39 & 0.05 & 0.33 & 0.05 & 0.52 & 0.05 \\
\hline 17:0, margaric & 1.2 & 0.16 & 1.1 & 0.16 & 1.4 & 0.16 \\
\hline 17:1, margaroleic & 1.2 & 0.10 & 1.3 & 0.10 & 0.9 & 0.10 \\
\hline 18:0, stearic & $9.0^{\mathrm{a}}$ & 1.26 & $8.5^{\mathrm{a}}$ & 1.26 & $14.5^{\mathrm{b}}$ & 1.26 \\
\hline $18: 1$, oleic & $39.9^{\mathrm{a}}$ & 1.80 & $47.1^{\mathrm{b}}$ & 1.80 & $36.1^{\mathrm{a}}$ & 1.80 \\
\hline trans $18: 1$, elaidic & 4.3 & 1.38 & 2.7 & 1.38 & 3.0 & 1.38 \\
\hline \multicolumn{7}{|l|}{$\%$ in sample of fat } \\
\hline cis monounsaturated fat & $40.4^{\mathrm{a}}$ & 3.93 & $42.1^{\mathrm{a}}$ & 3.93 & $21.9^{\mathrm{b}}$ & 3.93 \\
\hline cis polyunsaturated fat & 2.7 & 0.49 & 2.3 & 0.49 & 1.2 & 0.49 \\
\hline n-3 fat & 0.19 & 0.08 & 0.21 & 0.08 & 0.50 & 0.08 \\
\hline $\mathrm{n}-6$ fat & $2.5^{\mathrm{a}}$ & 0.44 & $2.1^{\mathrm{a}}$ & 0.44 & $0.68^{\mathrm{b}}$ & 0.44 \\
\hline $\mathrm{n}-6: \mathrm{n}-3$ ratio & $12.9^{\mathrm{a}}$ & 0.80 & $10.0^{\mathrm{a}}$ & 0.80 & $1.4^{\mathrm{b}}$ & 0.80 \\
\hline Saturated fat & 35.2 & 4.36 & 27.2 & 4.36 & 26.1 & 4.36 \\
\hline Total fat triglycerides & 86.6 & 9.05 & 77.9 & 9.05 & 53.7 & 9.05 \\
\hline trans fat & 4.3 & 1.37 & 2.8 & 1.37 & 2.2 & 1.37 \\
\hline
\end{tabular}

${ }^{\text {a-c }}$ Means within a row without common superscript letters are different at $P<0.05$.

GRS steers. These data indicate that FA composition may be altered by inclusion of pasture grass and more forage in the diet.

\section{Shear Force and Objective Color Scores}

Least squares means for WBSF values and objective color scores are given in Table 2. The GRS (2.6 $\mathrm{kg}$ ) steers had steaks that were not different for WBSF than ORG $(2.3 \mathrm{~kg})$ steaks; however, the GRS steaks tended $(P=0.08)$ to have greater shear force than the CONV $(2.0 \mathrm{~kg})$ steaks. In a study by Wheeler et al. (1997), a WBSF value less than $4.6 \mathrm{~kg}$ was associated with a sensory panel rating of slightly tender.

For objective color scores (Table 2), the GRS steaks (41.3) and ORG (40.0) steaks were not different from the CONV (42.4) steaks for $\mathrm{L}^{*}$ values. However, the GRS $(10.5)$ steaks had lower $(P<0.05) a^{*}$ values than CONV (14.5) steaks. The GRS (11.8), ORG (11.8), and CONV (14.4) steaks were not different for $b^{*}$ values.

Table 2. Least squares means and SE for Warner-Bratzler shear force and objective color scores for organically raised (pasture + concentrate and grass-fed) dairy steers compared with conventionally raised dairy steers

\begin{tabular}{|c|c|c|c|c|c|c|}
\hline \multirow[b]{3}{*}{ Measurement $^{1}$} & \multicolumn{6}{|c|}{ Dairy steers } \\
\hline & \multicolumn{2}{|c|}{ Conventional } & \multicolumn{2}{|c|}{ Organic } & \multicolumn{2}{|c|}{ Grass-fed organic } \\
\hline & LSM & $\mathrm{SE}$ & LSM & $\mathrm{SE}$ & LSM & $\mathrm{SE}$ \\
\hline WBSF $(\mathrm{kg})$ & 2.0 & 0.15 & 2.3 & 0.15 & 2.6 & 0.15 \\
\hline $\mathrm{L}^{*}$ & 42.4 & 1.1 & 40.0 & 1.1 & 41.3 & 1.1 \\
\hline$a^{*}$ & $14.5^{\mathrm{a}}$ & 0.75 & $11.4^{\mathrm{ab}}$ & 0.75 & $10.6^{\mathrm{b}}$ & 0.75 \\
\hline $\mathrm{b}^{*}$ & 14.4 & 0.65 & 11.8 & 0.65 & 11.8 & 0.65 \\
\hline
\end{tabular}

a,b Means within a row without common superscript letters are different at $P<0.05$.

${ }^{1} \mathrm{WBSF}=$ Warner-Bratzler shear force; $\mathrm{L}^{*}=$ brightness $(0=$ black; $100=$ white $) ; \mathrm{a}^{*}=$ redness $/$ greenness (positive values $=$ red; negative values $=$ green); $b^{*}=$ yellowness $/$ blueness $($ positive values $=$ yellow; negative values $=$ blue) . 
Table 3. Least squares means and SE for sensory attributes for organically raised (pasture + concentrate and grass-fed) dairy steers compared with conventionally raised dairy steers

\begin{tabular}{|c|c|c|c|c|c|c|}
\hline \multirow[b]{3}{*}{ Sensory attribute } & \multicolumn{6}{|c|}{ Dairy steers } \\
\hline & \multicolumn{2}{|c|}{ Conventional } & \multicolumn{2}{|c|}{ Organic } & \multicolumn{2}{|c|}{ Grass-fed organic } \\
\hline & LSM & SE & LSM & $\mathrm{SE}$ & LSM & $\mathrm{SE}$ \\
\hline Overall liking $^{1}$ & $69.2^{\mathrm{a}}$ & 1.50 & $71.3^{\mathrm{a}}$ & 1.50 & $56.3^{\mathrm{b}}$ & 1.50 \\
\hline Flavor liking & $69.2^{\mathrm{b}}$ & 1.50 & $73.3^{\mathrm{a}}$ & 1.50 & $56.8^{\mathrm{c}}$ & 1.50 \\
\hline Texture liking ${ }^{1}$ & $67.2^{\mathrm{a}}$ & 1.70 & $67.6^{\mathrm{a}}$ & 1.70 & $53.0^{\mathrm{b}}$ & 1.70 \\
\hline Toughness $^{2}$ & $7.4^{\mathrm{b}}$ & 0.39 & $8.0^{\mathrm{b}}$ & 0.39 & $10.1^{\mathrm{a}}$ & 0.39 \\
\hline Juiciness $^{2}$ & $6.3^{\mathrm{a}}$ & 0.31 & $5.5^{\mathrm{b}}$ & 0.31 & $3.9^{\mathrm{c}}$ & 0.31 \\
\hline Off-flavor ${ }^{2}$ & $4.1^{\mathrm{b}}$ & 0.37 & $3.9^{\mathrm{b}}$ & 0.37 & $6.3^{\mathrm{a}}$ & 0.37 \\
\hline
\end{tabular}

${ }^{a-c}$ Means within a row without common superscript letters are different at $P<0.05$.

${ }^{1}$ Overall flavor and texture liking/disliking: $0=$ greatest imaginable disliking; $120=$ greatest imaginable liking.

${ }^{2}$ Toughness, juiciness, and off-flavor: $0=$ none; $20=$ extremely tough, extremely juicy, or extremely intense.

Beef from grass-fed steers tends to be darker and the fat tends to be more yellow than grain-fed beef (Cox et al., 2006). Cozzi et al. (2010) reported that organic beef had greater $a^{*}$ values than conventional beef, which is in disagreement with the current study. Perhaps, genetic differences in livestock, forage quality, pasture species, and length of pasture grazing determine the color of the beef in an organic grazing system.

\section{Sensory Panel}

Least squares means and standard errors of means for sensory attributes are given in Table 3. For overall consumer liking, means were similar for ORG (71.3) and CONV (69.2) beef steaks; however, the GRS beef steaks were rated lower $(P<0.05)$ for overall liking than the ORG and CONV beef steaks. Furthermore, means for texture, toughness, and off-flavor were similar for ORG and CONV beef steaks. Surprisingly, the ORG (73.3) beef steaks had greater $(P<0.05)$ flavor ratings compared with the CONV (69.2) beef steaks. The flavor ratings were high for both ORG and CONV beef steaks; quite possibly, the ORG beef steaks had high ratings because they were fed concentrates during the grazing season and during the winter. These results are similar to those of French et al. (2000) and Roberts et al. (2009), who reported that feeding some concentrate with pasture forage improved the flavor characteristics of beef during sensory analysis. However, the overall liking of the CONV beef steaks may have been rated lower by consumers because they were in a freezer 2 mo longer than the ORG beef steaks. As expected, the GRS beef steaks had less $(P<0.05)$ flavor and texture, and the beef was tougher, less juicy, and exhibited more off-flavor. The results are similar to those of a study by Poulson et al. (2004) who found GRS beef had the highest off-flavor scores. Steinberg et al. (2009) reported that consumers found GRS steaks to be too tough and too dry, but consumers in their study did not dislike the beef.

For overall liking of beef (Table 4$)$, only $12.6 \%(P$ $<0.05$ ) of consumers moderately liked (scores of 81 to $120)$ the GRS steaks compared with ORG (30.0\%) and CONV $(32.0 \%)$ steaks. Only $2.7 \%$ of consumers liked the GRS steaks very much and no consumers extremely liked the GRS steaks. No differences were observed for ORG and CONV steaks for the consumer like/dislike categories. Consumer acceptability of GRS steaks in the marketplace is dependent on flavor and tenderness, and GRS beef had been noted to have a "grassy" flavor (Cox et al., 2006) and found to be less palatable for consumers than CONV beef (Daley et al., 2010). However, in the current study, $43.9 \%$ of consumers had a liking for the GRS beef steaks, which may indicate market potential for grass-fed beef in the United States. Cox et al. (2006) reported that one-third of consumers preferred grass-finished beef and were willing to pay a premium for the beef. In a similar study, Steinberg et al. (2009) reported that $23 \%$ of United States beef consumers preferred the taste of grass-fed beef and would pay a premium for the meat. Cattle producers should identify consumers of beef for specific niche markets, especially organic, to take advantage of feeding organic dairy steers grass.

\section{CONCLUSIONS}

Consumers are becoming more concerned about the origins of food, and grass-fed beef and organic beef have the potential to provide alternative beef products for consumers. The study evaluated FA profiles and consumer acceptance of organic dairy steers compared with conventional dairy steers. The fat from the grassfed steers was greater in n-3 FA and lower in monounsaturated and saturated fat. Consumers rated the grass-fed beef the lowest in overall liking and flavor; 
Table 4. Means for overall like/dislike categories for organically raised (pasture + concentrate and grass-fed) dairy steers compared with conventionally raised dairy steers

\begin{tabular}{lccc}
\hline & \multicolumn{3}{c}{ Dairy steers } \\
\cline { 2 - 4 } Sensory attribute $^{1}$ & Conventional & Organic & Grass-fed organic \\
\hline Like slightly, 60 to $120(\%)$ & $71.4^{\mathrm{a}}$ & $76.5^{\mathrm{a}}$ & $43.9^{\mathrm{b}}$ \\
Like moderately, 81 to $120(\%)$ & $32.0^{\mathrm{a}}$ & $30.0^{\mathrm{a}}$ & $12.6^{\mathrm{b}}$ \\
Like very much, 93 to $120(\%)$ & $8.5^{\mathrm{a}}$ & $8.8^{\mathrm{a}}$ & $2.7^{\mathrm{b}}$ \\
Like extremely, 104 to $120(\%)$ & $2.0^{\mathrm{a}}$ & $1.0^{\mathrm{ab}}$ & $0.0^{\mathrm{b}}$ \\
\hline
\end{tabular}

$\overline{a, b}$ Means from chi-squared test within a row without common superscript letters are different at $P<0.05$.

${ }^{1}$ Overall liking/disliking: 0 = greatest imaginable disliking; 120 = greatest imaginable liking.

however, $43.9 \%$ of consumers had at least a slight liking for the GRS steaks. Organic dairy bull calves may represent a potential resource for pasture-raised beef in the United States.

\section{ACKNOWLEDGMENTS}

The authors express gratitude to Darin Huot and coworkers at the University of Minnesota West Central Research and Outreach Center (Morris) for their assistance in data collection and care of animals. This study was supported by US Department of Agriculture North Central Sustainable Agriculture Research and Education (SARE) grant no. GNC12-150, "Effect of Growth, Meat Quality, and Profitability of Organically Raised Dairy-Beef Steers."

\section{REFERENCES}

AOAC International. 2002. AOAC Official Methods of Analysis. Method 996.06: Fat (total, saturated, and unsaturated) in foods. 17th ed. AOAC International, Gaithersburg, MD.

Bjorklund, E. A., B. J. Heins, A. DiCostanzo, and J. Chester-Jones. 2014. Growth, carcass characteristics, and profitability of organic versus conventional dairy beef steers. J. Dairy Sci. 97:1817-1827. 10.3168/jds.2013-6983.

CIE (Commission Internationale de l'Eclairage). 1976. Recommendations on uniform color spaces - Color-difference equations, psychometric color terms. Supplement No. 2 to CIE Publication No. 15 (E-1.3.1) 1971/(TC-1-3). CIE, Paris, France.

Cox, R. B., C. R. Kerth, J. G. Gentry, J. W. Prevatt, K. W. Braden, and W. R. Jones. 2006. Determining acceptance of domestic forage- or grain-finished beef by consumers from three southeastern U.S. states. J. Food Sci. 71:S542-S546.

Cozzi, G., M. Brscic, F. Da Ronch, A. Boukha, S. Tenti, and F. Gottardo. 2010. Comparison of two feeding finishing treatments on production and quality of organic beef. Ital. J. Anim. Sci. 9:404409
Daley, C. A., A. Abbott, P. S. Doyle, G. A. Nader, and S. Larson. 2010. A review of fatty acid profiles and antioxidant content in grass-fed and grain-fed beef. Nutr. J. 9:10.

Dimitri, C. and L. Oberholtzer. 2009. Marketing U.S. Organic Foods: Recent Trends From Farms to Consumers. Economic Information Bulletin No. 58. US Dept. of Agriculture, Economic Research Service, Washington, DC

French, P., E. G. O'Riordan, F. J. Monahan, P. J. Caffrey, M. Vidal, M. T. Mooney, D. J. Troy, and A. P. Moloney. 2000. Meat quality of steers finished on autumn grass, grass silage or concentratebased diets. Meat Sci. 56:173-180.

Gillespie, J., and R. Nehring. 2013. Comparing economic performance of organic and conventional U.S. beef farms using matching samples. Aust. J. Agric. Resour. Econ. 57:178-192.

NAMP (North American Meat Processors Association). 2002. The Meat Buyers Guide. NAMP, Reston, VA.

Poulson, C. S., T. R. Dhiman, A. L. Ure, D. Cornforth, and K. C. Olson. 2004. Conjugated linoleic acid content of beef from cattle fed diets containing high grain, CLA, or raised on forages. Livest. Prod. Sci. 91:117-128.

Priolo, A., D. Micol, and J. Agabriel. 2001. Effects of grass feeding systems on ruminant meat colour and flavour. A review. Anim. Res. 50:185-200.

Razminowicz, R. H., M. Kreuzer, and M. R. L. Scheeder. 2006. Quality of retail beef from two grass- based production systems in comparison with conventional beef. Meat Sci. 73:351-361.

Roberts, S. D., C. R. Kerth, K. W. Braden, D. L. Rankins Jr., L. Kriese-Anderson, and J. W. Prevatt. 2009. Finishing steers on winter annual ryegrass (Lolium multiforum Lam.) with varied levels of corn supplementation I: Effects on animal performance, carcass traits, and forage quality. J. Anim. Sci. 87:2690-2699.

SAS Institute. 2012. SAS/STAT Software. Release 9.3. SAS Institute Inc., Cary, NC.

Steinberg, E. L., V. H. Baumer, E. W. Mills, and J. W. Comerford 2009. Case study: Production and consumer characteristics of pasture-fed beef. Prof. Anim. Sci. 25:801-808.

USDA-NOP (USDA National Organic Program). 2012. The Program Handbook: Guidance and Instructions for Accredited Certifying Agents and Certified Operations. Accessed Jan. 25, 2012. http:// www.ams.usda.gov/AMSv1.0/nop.

Wheeler, T. L., S. D. Shackelford, and M. Koohmaraie. 1997. Standardizing collection and interpretation of Warner-Bratzler shear force and sensory tenderness data. Proc. Recip. Meat Conf. 50:68-77. 